\title{
Chemical Composition of Essential Oils from Six Zanthoxylum Species and Their Repellent Activities against Two Stored-Product Insects
}

\author{
Wen-Juan Zhang, ${ }^{1}$ Zhe Zhang, ${ }^{1}$ Zhen-Yang Chen, ${ }^{1}$ Jun-Yu Liang, ${ }^{1}$ Zhu-Feng Geng, ${ }^{1,2}$ \\ Shan-Shan Guo, ${ }^{1}$ Shu-Shan Du, ${ }^{1}$ and Zhi-Wei Deng ${ }^{2}$ \\ ${ }^{1}$ Beijing Key Laboratory of Traditional Chinese Medicine Protection and Utilization, Faculty of Geographical Science, \\ Beijing Normal University, Haidian District, Beijing 100875, China \\ ${ }^{2}$ Analytical and Testing Center, Beijing Normal University, Haidian District, Beijing 100875, China
}

Correspondence should be addressed to Shu-Shan Du; dushushan@bnu.edu.cn

Received 11 June 2017; Accepted 1 August 2017; Published 28 August 2017

Academic Editor: Franco Tassi

Copyright (C) 2017 Wen-Juan Zhang et al. This is an open access article distributed under the Creative Commons Attribution License, which permits unrestricted use, distribution, and reproduction in any medium, provided the original work is properly cited.

\begin{abstract}
The objective of this study was to analyze six essential oils from Zanthoxylum genus (family Rutaceae) in China and evaluate their repellent activities against Tribolium castaneum and Lasioderma serricorne adults. Six essential oils from Zanthoxylum genus, including Z. armatum, Z. dimorphophyllum, Z. dimorphophyllum var. spinifolium, Z. piasezkii, Z. stenophyllum, and Z. dissitum, were obtained by hydrodistillation and their yields were ranging from $0.02 \%$ to $0.53 \%$. Totally, there were 39 chemical components revealed by GC-MS. Among them, some components with high relative content existed in more than three Zanthoxylum species. For instance, both $\delta$-cadinene (1.21\%-17.15\%) and spathulenol (0.36\%-10.19\%) appeared in essential oils of $Z$. dimorphophyllum, $Z$. piasezkii, Z. stenophyllum, and $Z$. dissitum which were found to have higher content of sesquiterpenoids. The repellent activities of six essential oil samples against T. castaneum and L. serricorne adults were investigated for the first time. Data demonstrated that six Zanthoxylum species had much stronger repellent activities against T. castaneum than L. serricorne adults, especially in 2 hours after exposure. The results indicate that these six essential oils from Zanthoxylum have significant potential to be developed into natural repellents to control insects in grains, food, and traditional Chinese medicinal materials.
\end{abstract}

\section{Introduction}

Tribolium castaneum, the red flour beetle, and Lasioderma serricorne, the cigarette beetle, are two major destructive primary agricultural pests of stored grains, cereal foods, or traditional Chinese medicinal materials in both tropics and subtropics [1-3]. At warm and humid facilities, both of them can build up to huge populations very quickly. It was reported that these two stored insects could not only cause substantial quantitative and qualitative losses of stored commodities but also result in temperature raising and humidity conditions which lead to a promoted growth of harmful spoilage bacteria, molds, including toxigenic species. In recent years, many attempts, such as the hot air, the ionizing radiation, the cold storage, and the synthetic chemicals, have been made to control pests in storage. Among them, the heavily use of synthetic chemicals is the most popular method in controlling pests in storage. However, long time use of synthetic chemicals has led to a several of undesirable effects, including possible hazards to nontarget animals, risk to environmental pollution, and development of resistance by insects' resurgence [4-6]. Thus, finding out alternative ecologically safe, biodegradable, convenient, less persistent, low-cost, more pest specific methods to control stored insect is becoming more and more urgent. Recently, researchers have provided a novel conception of antagonistic storage, which could be tracing back to Ming dynasty of China [7]. It is a method using odorous Chinese herbs to store with medicinal herbs, which is vulnerable to insects, to avoid infestations and mildew and keep traditional Chinese 
TABLE 1: Collecting information of the six Zanthoxylum species.

\begin{tabular}{|c|c|c|c|c|c|}
\hline Species & Date & $\begin{array}{c}\text { Sample } \\
\text { mass } \\
(\mathrm{Kg})\end{array}$ & $\begin{array}{l}\text { Essential } \\
\text { oil volume } \\
\quad(\mathrm{mL})\end{array}$ & $\begin{array}{c}\text { Yield } \\
(\mathrm{V} / \mathrm{W} \%)\end{array}$ & Voucher specimens \\
\hline Zanthoxylum armatum DC. & 2015.09 & 1.60 & 8.48 & 0.53 & BNU-CMH-DuSS-2015-09-02-001 \\
\hline Zanthoxylum dimorphophyllum Hemsl. & 2015.09 & 0.40 & 0.52 & 0.13 & BNU-CMH-DuSS-2015-09-02-002 \\
\hline $\begin{array}{l}\text { Zanthoxylum dimorphophyllum Hemsl. } \\
\text { var. spinifolium Rehder et Wils. }\end{array}$ & 2015.09 & 0.60 & 1.68 & 0.28 & BNU-CMH-DuSS-2015-09-02-003 \\
\hline Zanthoxylum dissitum Hemsl. & 2015.09 & 1.10 & 0.55 & 0.05 & BNU-CMH-DuSS-2015-09-02-006 \\
\hline Zanthoxylum piasezkii Maxim. & 2015.09 & 0.52 & 2.50 & 0.48 & BNU-CMH-DuSS-2015-09-02-004 \\
\hline Zanthoxylum stenophyllum Hemsl. & 2015.12 & 3.00 & 0.60 & 0.02 & BNU-CMH-DuSS-2015-12-02-005 \\
\hline
\end{tabular}

medicinal herbs in good color. Therefore, as the secondary metabolism of aromatic plants, volatile essential oils have drawn more and more attention. Currently, a great number of essential oils from natural plants have been investigated, and some of them have turned out to possess strong insecticidal, repellent, and feeding deterrent effects [8-11].

Zanthoxylum is the largest and the most widespread genus in the Rutaceae, comprising approximately 250 species, and is widely distributed in the temperate and tropical regions, of which there are 45 species and 13 varieties in China $[12,13]$. Traditionally, members of them with pungent taste are often used as condiments in both Eastern Asian countries and Central America [14]. Also, Zanthoxylum species have a folklore history in the treatment of various diseases, such as inflammation [15], toothache, lumbago [16], ascarid infection [17], sickle-cell anaemia, and malaria. Literatures have also shown that Zanthoxylum species possess a potential antiinsect [7, 18, 19], antimicrobial [20], antibacterial [21], and antifungal [22] activities.

To inherit and develop Chinese traditional method of antagonistic storage, the repellent activities against $T$. castaneum and L. serricorne of essential oils from six Zanthoxylum species, including Zanthoxylum armatum, Zanthoxylum dimorphophyllum, Zanthoxylum dimorphophyllum var. spinifolium, Zanthoxylum piasezkii, Zanthoxylum stenophyllum, and Zanthoxylum dissitum were investigated for the first time, and their chemical composition was evaluated as well. What is more, the chemical composition of essential oils from Z. dimorphophyllum, Z. piasezkii, and Z. stenophyllum was reported for the first time.

\section{Experimental}

2.1. Experimental Samples and the Extraction of Essential Oils. The experimental samples were collected from mature plants in Wen County (32.59N, 104.69E) of Gansu province, China. All the plant samples were identified by Professor Liu, Q. R. (College of Life Sciences, Beijing Normal University, Beijing, China) and voucher specimens in Table 1 were deposited at the herbarium (BNU) of Faculty of Geographical Science, Beijing Normal University. The branches and leaves of the six Zanthoxylum species were air dried and grounded to powders. The six sample powders were subjected to hydrodistillations using a modified Clevenger type apparatus as we described in our recent investigation for 6 hours, respectively [23]. Anhydrous sodium sulfate was used to remove extra water. Then, the six essential oil samples were stored in dark airtight containers in a refrigerator at $4^{\circ} \mathrm{C}$.

\subsection{Insects. Tribolium castaneum and Lasioderma serricorne} were identified by Professor Liu, Z. L. (College of Plant Protection, China Agricultural University, Beijing, China). Culture of the red flour beetles and the cigarette beetle followed the same method mentioned in our recent literature [24]. Both of them were obtained from laboratory cultures maintained in the dark in incubators at $29-30^{\circ} \mathrm{C}$ and $70 \%-80 \%$ relative humidity $(\mathrm{RH})$. They were reared in glass containers $(0.5 \mathrm{~L})$ containing wheat flour mixed with yeast $(10: 1, \mathrm{w} / \mathrm{w})$ at $12 \%-13 \%$ moisture content. The unsexed adults used in all the experiments were about $7 \pm 2$ days old. All culture containers used in experiments were made escape proof with a coating of polytetrafluoroethylene (Sino-rich ${ }^{\circledR}$, Beijing Sino-rich Tech Co., Ltd., Xuanwu District, Beijing, China).

2.3. Gas Chromatography and Mass Spectrometry. GC analysis of six essential oil samples was performed by a Thermo Finnigan Trace DSQ GC/MS instrument (Thermo Finnigan, Lutz, FL, USA) equipped with a flame ionization detector (FID) and a capillary column of HP-5MS (30 $\mathrm{m} \times 0.25 \mathrm{~mm}$ $\times 0.25 \mu \mathrm{m})$. The mass spectrometer was operated in the electron-impact mode, with ionization energy of $70 \mathrm{eV}$ in $\mathrm{m} / \mathrm{e}$ ranging 10-550 amu. In GC-FID and GC-MS analysis, the same column and analysis conditions as described in our recent study [23] were used. The temperature was programmed isothermal at $50^{\circ} \mathrm{C}$ for 2 minutes, rising up from 50 to $150^{\circ} \mathrm{C}$ at the speed of $2^{\circ} \mathrm{C} / \mathrm{min}$, then held isothermal at $150^{\circ} \mathrm{C}$ for 2 minutes, rising up from 150 to $250^{\circ} \mathrm{C}$ at a high speed of $10^{\circ} \mathrm{C} / \mathrm{min}$, and finally was kept isothermal at $250^{\circ} \mathrm{C}$ for 5 minutes. The injector temperature was $250^{\circ} \mathrm{C}$, and the flow rate of carrier gas (helium) was $1.0 \mathrm{~mL} / \mathrm{min}$. Samples were diluted in hexane and then injected in the split mode. Identification of components by gas chromatography/mass spectrometry is a good literature for retention indices of chemical components of essential oils [25]. Quantification was determined by percentage peak area calculation using GC-FID, and some chemical components were identified by coinjections with standard (wherever possible) and confirmed by using the National Institute of Standards and Technology (NIST) version 05 GC-MS libraries (Standard 
Reference Data, Gaithersburg, MD, USA) and Wiley 275 mass-spectral libraries (Wiley, New York, NY, USA) or in the literature [26-28]. Relative percentages of each component in the essential oil samples were obtained by averaging the GCFID peak area\% reports.

2.4. Repellency Tests. A modified area preference method $[24,29]$ was performed to the repellent activity against T. castaneum and L. serricorne adults for all essential oil samples. The six testing essential oil samples were dissolved separately in $n$-hexane to five different testing concentrations $\left(78.63,15.73,3.15,0.63\right.$, and $\left.0.13 \mathrm{~nL} / \mathrm{cm}^{2}\right)$. As experimental containers, Petri dishes $(9 \mathrm{~cm}$ in diameter) were used to housing T. castaneum and L. serricorne adults. All the Petri dishes were pretreated with polytetrafluoroethylene (Sinorich $^{\circledR}$, Beijing Sino-rich Tech Co., Ltd., Xuanwu District, Beijing, China) on the wall to prevent insects from escaping during repellent test. Every filter paper $(9 \mathrm{~cm}$ in diameter) used was cut into two equal pieces. One piece was treated with $500 \mu \mathrm{L}$ of testing solution, while another piece was added with the same volume of $n$-hexane as blank control. After air drying for $30 \mathrm{~s}$, the two pieces of filter paper were carefully fixed with solid glue on the bottom of a Petri dish side by side tightly. During each test, twenty insects were released at the center of the disk and then covered quickly with dish cover. Counting of insects was performed very carefully on each half piece of paper at 2 and $4 \mathrm{~h}$ after exposure, respectively. Five replicates were performed for each tested concentration and each test was repeated for three times. Meanwhile, N,Ndiethyl-3-methylbenzamide, DEET, a commercial repellent purchased from Dr. Ehrenstorfer (Augsburg, Germany) was used as a positive control. For each essential oil sample, the value of percent repellency (PR) was calculated as follows:

$$
\operatorname{PR}(\%)=\left[\frac{(N c-N t)}{(N c+N t)}\right] \times 100,
$$

$N c$ was the number of insects on the control half, while $N t$ was the number of insects on the opposite side of testing. Analysis of variance (one-way ANOVA with Tukey post hoc test) was conducted by using Origin 2016 software.

\section{Results and Discussion}

3.1. Chemical Composition of the Essential Oil. Chemical components of essential oils from six Zanthoxylum species, including $Z$. armatum, $Z$. dimorphophyllum, $Z$. dimorphophyllum var. spinifolium, $Z$. piasezkii, Z. stenophyllum, and $Z$. dissitum were presented in Table 2. The yields of essential oils obtained from six Zanthoxylum genus ranged from $0.02 \%$ to $0.53 \%(\mathrm{v} / \mathrm{w} \%)$. Though there are similarities in some of essential oil samples, their main components were quite different. For instance, the major components of $Z$. armatum essential oil were $\beta$-terpinene (45.56\%), piperitone (33.47\%), and 3-carene (8.88\%), whereas $\beta$-caryophyllene, caryophyllene oxide, spathulenol, and $\delta$-cadinene were the principal constituents of $Z$. dimorphophyllum essential oil with the relative contents of $26.17 \%, 13.36 \%, 10.19 \%$, and $8.58 \%$, respectively. As one of the main compounds, safrole only appeared in the essential oil of $Z$. dimorphophyllum var. spinifolium, while, as one of common chemical compound, eucalyptol turned out to exist only in $Z$. piasezkii essential oil. $\alpha$-Cubebene, as a main compound of $Z$. stenophyllum, also appeared in the essential oil of $Z$. dimorphophyllum. The major constituents of $Z$. dissitum volatile oil were $\gamma$-pyronene (21.97\%), germacrene $\mathrm{D}(20.98 \%), \delta$-cadinene $(17.15 \%)$, and $\alpha$-farnesene (14.28\%). Unlike the essential oil samples of $Z$. dimorphophyllum, Z. stenophyllum, and Z. dissitum consisting mostly of sesquiterpenoids, essential oils from $Z$. armatum and $Z$. piasezkii consisted mostly of monoterpenoids. Interestingly, as the lower taxa, the chemical components of essential oil from $Z$. dimorphophyllum var. spinifolium varies from $Z$. dimorphophyllum. Different original place and different harvest time might result in different chemical composition for the same plant essential oil. In one recent report [18], the main components from $Z$. armatum essential oil harvested in June in India were 2-undecanone (19.75\%), followed by 2 -tridecanone (11.76\%) and $\beta$-caryophyllene (9.88\%). What is more, different extract parts also resulted in different chemical component. A recent literature [30] showed that the chemical compounds of $Z$. dissitum essential oils extracted from leaves and roots were significantly different. The major compounds of essential oil from $Z$. dissitum leaves were $\delta$ cadinol (12.8\%), caryophyllene (12.7\%), $\beta$-cubebene (7.9\%), and 4-terpineol (7.5\%), while the main components from $Z$. dissitum roots essential oil were humulene epoxide II (29.4\%) and caryophyllene oxide (24.0\%). Z. dimorphophyllum var. spinifolium leaves harvested in April in the same place as our sample turned out to have different chemical composition [31]. Unlike our study, the main compounds of the essential oil from $Z$. dimorphophyllum var. spinifolium leaves reported by them were myristicin (24.85\%), safrole (20.47\%), and methyl eugenol (19.76\%). Despite these reports, there is the first report on chemical component analysis for $Z$. dimorphophyllum, Z. piasezkii, and Z. stenophyllum.

3.2. Repellent Activity. Among various investigated plants, the Zanthoxylum genus stands out for its extracts and essential oils exhibited insecticidal, fungicidal, antibacterial, and fumigant activities $[16,19,22]$. Here, we first report repellent activities of six Zanthoxylum species including Z. armatum, $Z$. dimorphophyllum, $Z$. dimorphophyllum var. spinifolium, $Z$. piasezkii, Z. stenophyllum, and $Z$. dissitum against two storage pests including T. castaneum and L. serricorne adults.

The results of the repellent activities of the essential oils from these six Zanthoxylum species were presented in Figures 1 and 2. It demonstrated that all essential oil samples exhibited obvious repellent activities against two stored insects. At tested concentrations of $78.63,15.73,3.15$, and $0.13 \mathrm{~nL} / \mathrm{cm}^{2}$, all of the six volatile oils exhibited higher repellency than the positive control of DEET against T. castaneum at 2 hours after exposure. Even exposed for 4 hours, these six essential oils also showed high repellent activities against $T$. castaneum. Among these essential oil samples, Z. armatum essential oil turned out to be the most effective repellent against $T$. castaneum at both 2 and $4 \mathrm{~h}$ after exposure. This might be attributed to its high content of monoterpenoids, which account for $93.62 \%$ of total essential oil. Unlike the repellency on T. castaneum, data in Figure 2 showed that essential oils 
TABLE 2: Chemical composition of essential oils from the six Zanthoxylum species.

\begin{tabular}{|c|c|c|c|c|c|c|c|c|c|}
\hline \multirow[b]{2}{*}{ Compound } & \multicolumn{8}{|c|}{ Relative content (\%) } & \multirow[b]{2}{*}{$\begin{array}{l}\text { Identification } \\
\text { methods }^{c}\end{array}$} \\
\hline & $\begin{array}{c}Z . \\
\text { armatum }\end{array}$ & $\begin{array}{l}\text { Z. dimorpho- } \\
\text { phyllum }\end{array}$ & $\begin{array}{l}\text { Z. dimorpho- } \\
\text { phyllum var. } \\
\text { spinifolium }\end{array}$ & Z. piasezkii & $\begin{array}{c}\text { Z. } \\
\text { stenophyllum }\end{array}$ & Z. dissitum & $\mathrm{RI}^{\mathrm{a}}$ & $\mathrm{RI}^{\mathrm{b}}$ & \\
\hline Camphene & - & - & - & 2.45 & - & - & 943 & 941 & RI, MS \\
\hline$\beta$-Thujene & - & - & - & 3.56 & - & - & 969 & 965 & RI, MS \\
\hline$\beta$-Pinene & - & - & - & - & 4.80 & - & 977 & 983 & RI, MS, Co \\
\hline 3-Carene & 8.88 & - & - & 0.62 & 8.30 & - & 1004 & 1006 & RI, MS \\
\hline Eucalyptol & - & - & - & 74.87 & - & - & 1017 & 1037 & RI, MS \\
\hline 4-Carene & 2.48 & - & - & - & - & - & 1018 & 1014 & RI, MS \\
\hline$\beta$-Phellandrene & 3.96 & - & - & - & - & - & 1026 & 1029 & RI, MS \\
\hline$\beta$-Terpinene & 45.56 & - & - & - & 4.21 & - & 1044 & 1045 & RI, MS \\
\hline$\gamma$-Terpinene & 3.23 & - & - & 0.34 & - & - & 1060 & 1065 & RI, MS \\
\hline neo-allo-Ocimene & - & - & - & - & 3.02 & - & 1147 & 1144 & RI, MS \\
\hline Terpinen-4-ol & - & - & - & 4.47 & 0.61 & - & 1162 & 1176 & RI, MS \\
\hline$\alpha$-Terpineol & - & - & - & 4.57 & - & - & 1181 & 1191 & RI, MS, Co \\
\hline Estragole & - & - & - & - & 5.19 & - & 1195 & 1191 & RI, MS \\
\hline Piperitone & 33.47 & 0.85 & 0.12 & - & - & - & 1227 & 1221 & RI, MS \\
\hline$\gamma$-Pyronene & - & - & 4.23 & - & - & 21.97 & 1250 & 1252 & RI, MS \\
\hline 2-Undecanone & - & - & - & - & 1.92 & - & 1265 & 1274 & RI, MS \\
\hline Bornyl acetate & - & - & - & - & 10.05 & - & 1272 & 1277 & RI, MS \\
\hline Safrole & - & - & 38.08 & - & - & - & 1285 & 1281 & RI, MS \\
\hline$\alpha$-Cubebene & - & 6.75 & - & - & 12.05 & - & 1350 & 1359 & RI, MS \\
\hline$\alpha$-Copaene & - & - & - & - & 0.43 & - & 1372 & 1375 & RI, MS \\
\hline Isoledene & - & - & - & - & 1.81 & - & 1376 & 1371 & RI, MS \\
\hline Geranyl acetate & - & - & - & - & 1.66 & - & 1379 & 1386 & RI, MS \\
\hline Methyl eugenol & - & 6.21 & 23.49 & - & - & - & 1384 & 1387 & RI, MS \\
\hline$\beta$-Elemene & - & 4.89 & 0.18 & 0.41 & 11.44 & 1.02 & 1388 & 1398 & RI, MS \\
\hline$\beta$-Caryophyllene & 0.51 & 26.17 & 4.00 & - & 7.16 & 7.77 & 1414 & 1418 & RI, MS \\
\hline$\alpha$-Caryophyllene & - & 3.78 & 0.28 & 1.15 & 2.48 & 4.65 & 1454 & 1453 & RI, MS \\
\hline$\gamma$-Muurolene & - & 0.75 & - & 1.06 & 1.14 & - & 1465 & 1462 & RI, MS \\
\hline$\gamma$-Gurjunene & - & 3.40 & - & - & 0.68 & - & 1474 & 1475 & RI, MS \\
\hline Germacrene D & - & - & 0.84 & - & 5.73 & 20.98 & 1477 & 1479 & RI, MS \\
\hline 2-Tridecanone & - & - & - & - & 0.61 & - & 1481 & 1485 & RI, MS \\
\hline Valencene & - & 0.79 & - & - & - & - & 1484 & 1481 & RI, MS \\
\hline$\alpha$-Farnesene & - & - & - & - & - & 14.28 & 1505 & 1508 & RI, MS \\
\hline Myristicin & - & 6.75 & 28.74 & - & - & - & 1513 & 1510 & RI, MS \\
\hline$\delta$-Cadinene & - & 8.58 & - & 1.21 & 7.27 & 17.15 & 1520 & 1524 & RI, MS \\
\hline Spathulenol & - & 10.19 & - & 0.36 & 1.85 & 4.42 & 1563 & 1561 & RI, MS \\
\hline Nerolidol & - & - & - & - & 2.85 & - & 1566 & 1564 & RI, MS \\
\hline Caryophyllene oxide & - & 13.36 & - & - & - & 4.32 & 1583 & 1585 & RI, MS \\
\hline Viridiflorol & - & 6.50 & - & - & - & - & 1592 & 1595 & RI, MS \\
\hline$\tau$-Cadinol & - & - & - & 0.53 & - & - & 1640 & 1643 & RI, MS \\
\hline Monoterpenoids & 93.62 & 0.85 & 42.43 & 90.88 & 26.13 & 21.97 & & & \\
\hline Sesquiterpenoids & 4.47 & 85.16 & 5.30 & 4.19 & 54.89 & 74.59 & & & \\
\hline Others & - & 12.96 & 52.23 & - & 14.24 & - & & & \\
\hline Total & 98.09 & 98.97 & 99.96 & 95.07 & 95.26 & 96.56 & & & \\
\hline
\end{tabular}

${ }^{\mathrm{a}} \mathrm{RI}$, retention index of the chromatography determined on a HP-5MS column using the homologous series of $n$-hydrocarbons as reference; ${ }^{\mathrm{b}} \mathrm{RI}$, retention index reported in the literatures or libraries. ${ }^{c}$ Identification method: RI, comparison of retention indices with published data; MS, comparison of mass spectra with those listed in the NIST 05 and Wiley 275 libraries and with published data; Co, coinjection with standard compound. 

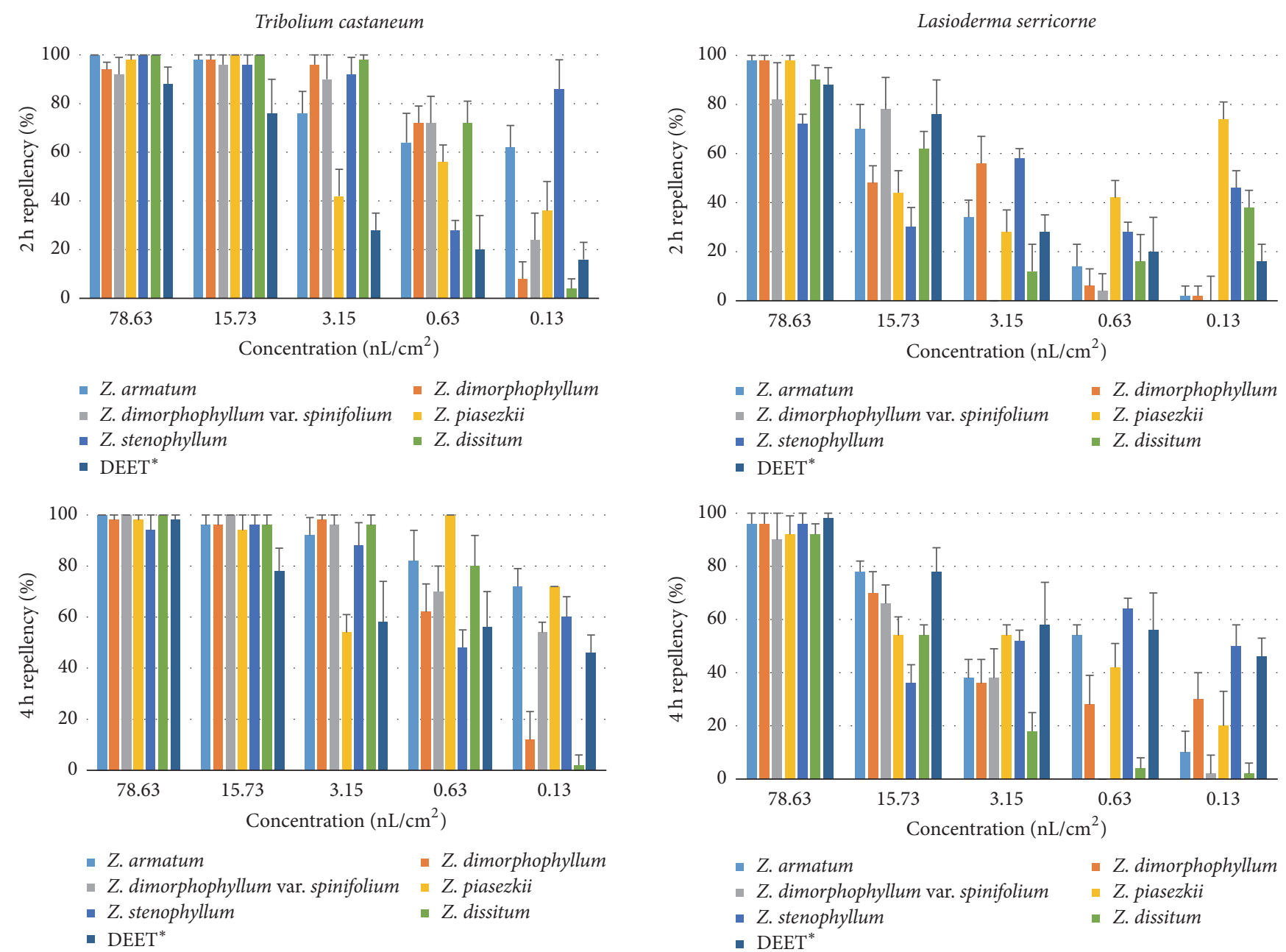

Figure 1: Percentage repellency (PR) of the essential oils from six Zanthoxylum species against $T$. castaneum at 2 and $4 \mathrm{~h}$ after exposure. ${ }^{*}$ Data from Yang et al. [23].

possessed high repellent activity against $L$. serricorne adults only at the highest concentration of $78.63 \mathrm{~nL} / \mathrm{cm}^{2}$. Mostly, the repellent activity against $L$. serricorne adults decreased obviously when the concentration diluted. However, Z. stenophyllum essential oil showed higher repellent activity against L. serricorne than the positive control of DEET at lower concentrations of 3.15 and $0.63 \mathrm{~nL} / \mathrm{cm}^{2}$ at both 2 and $4 \mathrm{~h}$ after exposure. As secondary metabolites of natural plants, these essential oils with abundant resources have potential for the development as botanical repellents. The different repellent activities on two insects might be attributed to the different anti-insect mechanism and different nonpersistent volatility of essential oil samples. Since there are no sufficient reports about it at present, further investigations need to be conducted in the future.

\section{Conclusions}

In this study, we investigated the chemical composition of six essential oils from Zanthoxylum species; among them, the

chemical constituents of essential oils from $Z$. dimorphophyllum, Z. piasezkii, and Z. stenophyllum were reported for the first time. What is more, repellent activities of these six essential oil samples against T. castaneum and L. serricorne adults were evaluated for the first time. It demonstrated that the essential oils of these six Zanthoxylum species essential oils possessed significant repellent activities against $T$. castaneum and L. serricorne adults. According to their abundant natural resources, these six essential oils of Zanthoxylum species with significant repellent activity might be developed into novel repellents to supply or substitute the heavy application of conventional repellents. Although further detailed investigations are needed, the above results can not only provide comprehensive utilization of plant resources of Zanthoxylum genus but also establish a very good perspective of novel application in control of stored-product insects.

\section{Conflicts of Interest}

The authors declare that there are no conflicts of interest regarding the publication of this paper. 


\section{Acknowledgments}

This project was supported by the National Key Research and Development Program (2016YFC0500805), Beijing Municipal Natural Science Foundation (no. 7142093), and Fundamental Research Funds for the Central Universities.

\section{References}

[1] Z. L. Liu and S. H. Ho, "Bioactivity of the essential oil extracted from Evodia rutaecarpa Hook $\mathrm{f}$. et Thomas against the grain storage insects, Sitophilus zeamais Motsch. and Tribolium castaneum (Herbst)," Journal of Stored Products Research, vol. 35, no. 4, pp. 317-328, 1999.

[2] A. T. Saroukolai, S. Moharramipour, and M. H. Meshkatalsadat, "Insecticidal properties of Thymus persicus essential oil against Tribolium castaneum and Sitophilus oryzae," Journal of Pest Science, vol. 83, no. 1, pp. 3-8, 2010.

[3] J. R. Ashworth, "The biology of Lasioderma serricorne," Journal of Stored Products Research, vol. 29, no. 4, pp. 291-303, 1993.

[4] J. L. Zettler and F. H. Arthur, "Chemical control of stored product insects with fumigants and residual treatments," Crop Protection, vol. 19, no. 8-10, pp. 577-582, 2000.

[5] D. H. Kim and Y. J. Ahn, "Contact and fumigant activities of constituents of Foeniculum vulgare fruit against three coleopteran stored-product insects," Pest Management Science, vol. 57, no. 3, pp. 301-306, 2001.

[6] Y. Omae, T. Fuchikawa, S. Nakayama et al., "Life history and mating behavior of a black-bodied strain of the cigarette beetle Lasioderma serricorne (Coleoptera: Anobiidae)," Applied Entomology and Zoology, vol. 47, no. 2, pp. 157-163, 2012.

[7] W.-J. Zhang, S.-S. Guo, C.-X. You et al., "Chemical composition of essential oils from Zanthoxylum bungeanum maxim. and their bioactivities against Lasioderma serricorne," Journal of Oleo Science, vol. 65, no. 10, pp. 871-879, 2016.

[8] H. P. Chen, K. Yang, C. X. You et al., "Chemical constituents and insecticidal activities of the essential oil of Cinnamomum camphora leaves against Lasioderma serricorne," Journal of Chemistry, vol. 2014, Article ID 963729, 5 pages, 2014.

[9] K. Yang, C. F. Wang, C. X. You et al., "Bioactivity of essential oil of Litsea cubeba from China and its main compounds against two stored product insects," Journal of Asia-Pacific Entomology, vol. 17, no. 3, pp. 459-466, 2014.

[10] Y. Liang, J. L. Li, S. Xu et al., "Evaluation of repellency of some chinese medicinal herbs essential oils against Liposcelis bostrychophila (Psocoptera: Liposcelidae) and Tribolium castaneum (Coleoptera: Tenebrionidae)," Journal of Economic Entomology, vol. 106, no. 1, pp. 513-519, 2013.

[11] C.-F. Wang, C.-X. You, K. Yang et al., "Antifeedant activities of methanol extracts of four Zanthoxylum species and benzophenanthridines from stem bark of Zanthoxylum schinifolium against Tribolium castaneum," Industrial Crops and Products, vol. 74, pp. 407-411, 2015.

[12] J. R. Pirani, "A new species and a new combination in Zanthoxylum (Rutaceae) from Brazil,” Brittonia, vol. 45, no. 2, pp. 154158, 1993.

[13] Z.-F. Zhao, R.-X. Zhu, K. Zhong, Q. He, A.-M. Luo, and H. Gao, "Characterization and comparison of the pungent components in commercial Zanthoxylum bungeanum oil and Zanthoxylum schinifolium oil," Journal of Food Science, vol. 78, no. 10, pp. C1516-C1522, 2013.
[14] F. Epifano, M. Curini, M. C. Marcotullio, and S. Genovese, "Searching for novel cancer chemopreventive plants and their products: the genus Zanthoxylum," Current Drug Targets, vol. 12, no. 13, pp. 1895-1902, 2011.

[15] P.-H. Nguyen, B. T. Zhao, O. Kim et al., "Anti-inflammatory terpenylated coumarins from the leaves of Zanthoxylum schinifolium with $\alpha$-glucosidase inhibitory activity," Journal of Natural Medicines, vol. 70, no. 2, pp. 276-281, 2016.

[16] Z. L. Liu, S. S. Chu, and G. H. Jiang, "Feeding deterrents from Zanthoxylum schinifolium against two stored-product insects," Journal of Agricultural and Food Chemistry, vol. 57, no. 21, pp. 10130-10133, 2009.

[17] M.-K. Han, S.-I. Kim, and Y.-J. Ahn, "Insecticidal and antifeedant activities of medicinal plant extracts against Attagenus unicolor japonicus (Coleoptera: Dermestidae)," Journal of Stored Products Research, vol. 42, no. 1, pp. 15-22, 2006.

[18] V. Kumar, S. G. E. Reddy, U. Chauhan, N. Kumar, and B. Singh, "Chemical composition and larvicidal activity of Zanthoxylum armatum against diamondback moth, Plutella xylostella," Natural Product Research, vol. 30, no. 6, pp. 689-692, 2016.

[19] M. Christofoli, E. C. C. Costa, K. U. Bicalho et al., "Insecticidal effect of nanoencapsulated essential oils from Zanthoxylum rhoifolium (Rutaceae) in Bemisia tabaci populations," Industrial Crops and Products, vol. 70, pp. 301-308, 2015.

[20] W. L. Nana, P. Eke, R. Fokom et al., "Antimicrobial Activity of Syzygium aromaticum and Zanthoxylum xanthoxyloides Essential Oils Against Phytophthora megakarya," Journal of Phytopathology, vol. 163, no. 7-8, pp. 632-641, 2015.

[21] W.-R. Diao, Q.-P. Hu, S.-S. Feng, W.-Q. Li, and J.-G. Xu, "Chemical composition and antibacterial activity of the essential oil from green huajiao (Zanthoxylum schinifolium) against selected foodborne pathogens," Journal of Agricultural and Food Chemistry, vol. 61, no. 25, pp. 6044-6049, 2013.

[22] J. A. Prieto, O. J. Patiño, W. A. Delgado, J. P. Moreno, and L. E. Cuca, "Chemical composition, insecticidal, and antifungal activities of fruit essential oils of three Colombian Zanthoxylum species," Chilean Journal of Agricultural Research, vol. 71, no. 1, pp. 73-82, 2011.

[23] K. Yang, C.-X. You, C.-F. Wang et al., "Composition and repellency of the essential oils of evodia calcicola chun ex huang and evodia trichotoma (lour.) pierre against three stored product insects," Journal of Oleo Science, vol. 63, no. 11, pp. 11691176, 2014.

[24] Z.-G. Ma, J. Zhang, L. Yang, and J.-Y. Ma, "Analysis and comparison of the volatile oil from different parts of Zanthoxylum ovalifolium var. spinifolium by GC-MS," Chinese Pharmaceutical Journal, vol. 39, no. 7, pp. 502-503, 2004.

[25] C.-X. You, Y. Wang, W.-J. Zhang et al., "Chemical constituents and biological activities of the Purple Perilla essential oil against Lasioderma serricorne," Industrial Crops and Products, vol. 61, pp. 331-337, 2014.

[26] C.-X. You, S.-S. Guo, Z.-F. Geng et al., "Repellent activity of compounds from Murraya alata Drake against Tribolium castaneum," Industrial Crops and Products, vol. 95, pp. 460-466, 2017.

[27] R. P. Adam, "Identification of essential oil components by gas chromatography/quadrupole mass spectrometry," Journal of the American Society for Mass Spectrometry, vol. 16, pp. 1902-1903, 2001.

[28] M. Sakuma, "Probit analysis of preference data," Applied Entomology and Zoology, vol. 33, no. 3, pp. 339-347, 1998. 
[29] R. J. Cannon, A. Kazimierski, N. L. Curto et al., "Identification, synthesis, and characterization of novel sulfur-containing volatile compounds from the in-depth analysis of lisbon lemon peels (Citrus limon L. Burm. f. cv. Lisbon)," Journal of Agricultural and Food Chemistry, vol. 63, no. 7, pp. 1915-1931, 2015.

[30] K.-M. Chang and G.-H. Kim, "Comparative chemical composition of domestic and imported Chrysanthemum indicum L. flower oils," Food Science and Biotechnology, vol. 18, no. 5, pp. 1288-1292, 2009.

[31] J. S. Zhang, N. N. Zhao, Q. Z. Liu et al., "Repellent constituents of essential oil of Cymbopogon distans aerial parts against two stored-product insects," Journal of Agricultural and Food Chemistry, vol. 59, no. 18, pp. 9910-9915, 2011. 

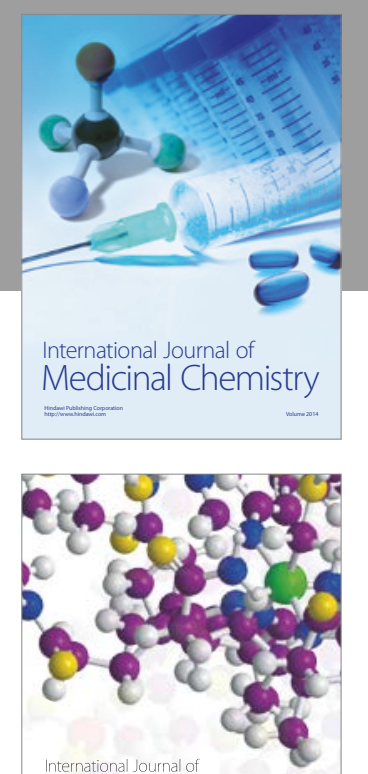

Carbohydrate Chemistry

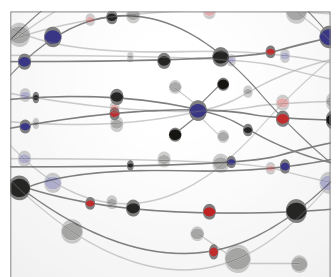

The Scientific World Journal
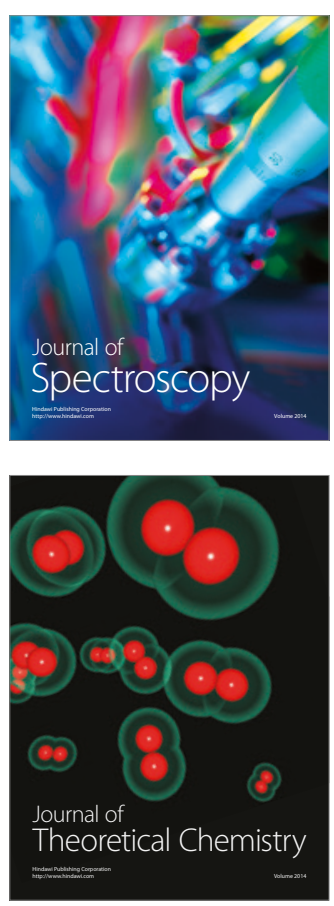
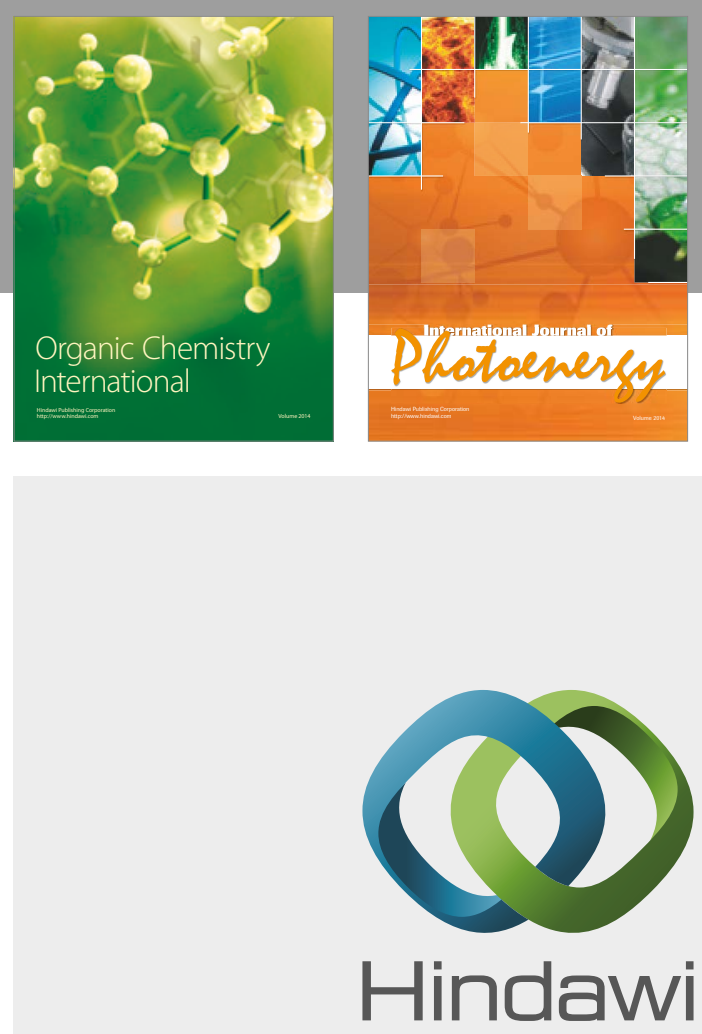

Submit your manuscripts at

https://www.hindawi.com

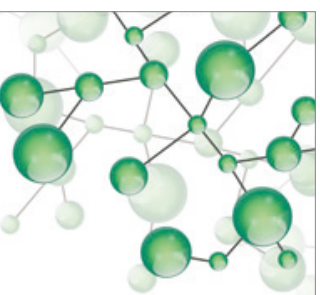

International Journal of

Inorganic Chemistry

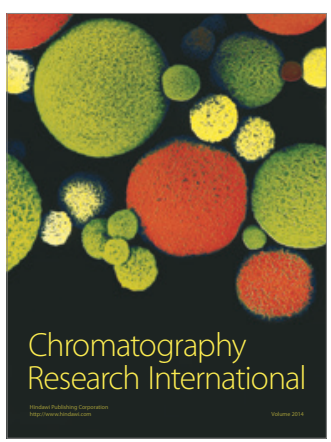

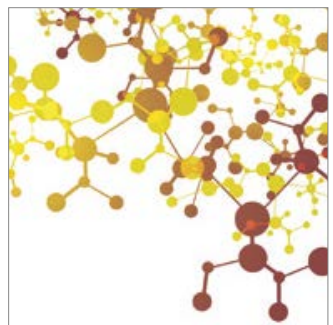

Applied Chemistry
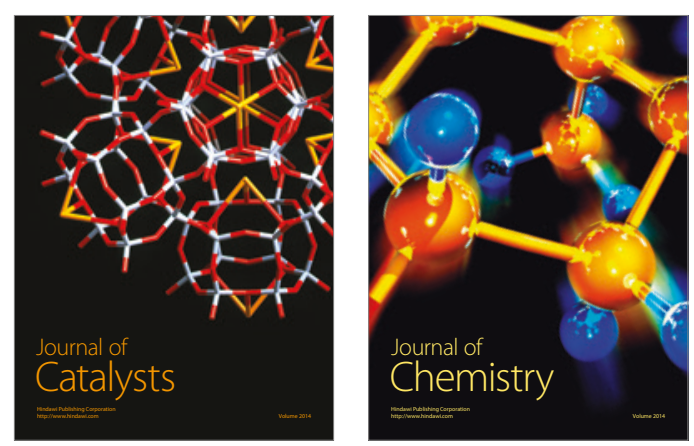
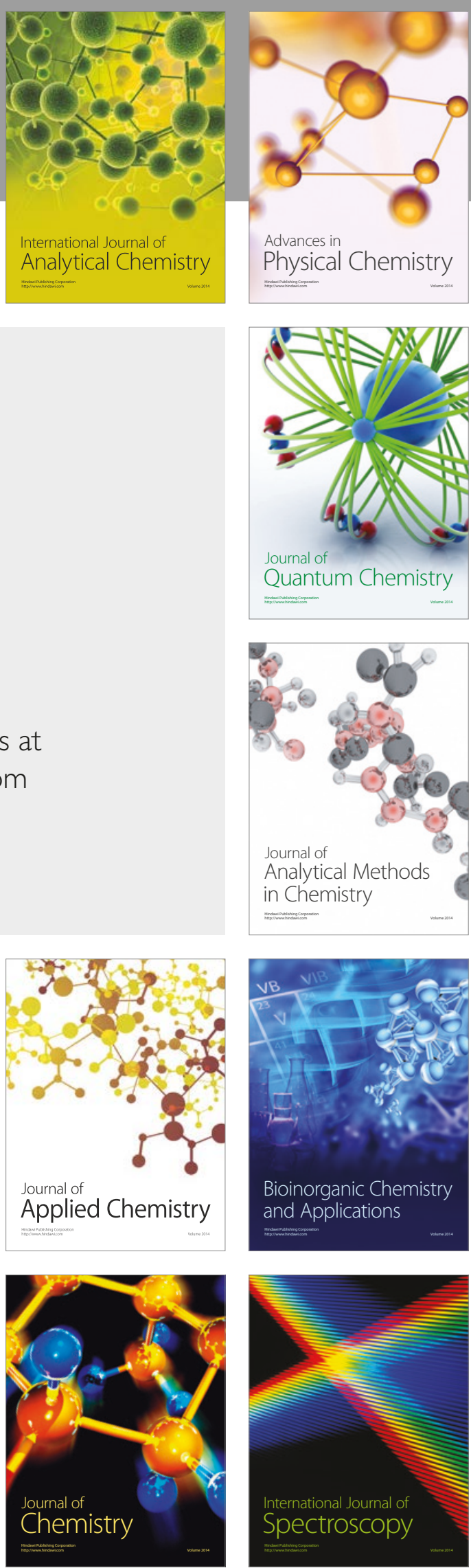